\title{
Sh-MARCH8 Inhibits Tumorigenesis via PI3K Pathway in Gastric Cancer
}

\author{
Junfeng Yin ${ }^{a}$ Ze Jib Yidong Hong ${ }^{c}$ Ziyan Song ${ }^{c} \quad \mathrm{Nan} \mathrm{Hu}^{c}$ \\ Min Zhuang ${ }^{c}$ Baoxiang Bian ${ }^{c}$ Yi Liu ${ }^{d}$ Fenglei $W^{c}$
}

aDepartment of General Surgery, The Affiliated Hospital of Yangzhou University, Yangzhou University, Yangzhou, bDepartment of Respiratory Medicine, Suzhou Kowloon Hospital, Shanghai Jiaotong University School of Medicine, Suzhou, 'Department of Oncology, Affiliated Lianyungang Hospital of Xuzhou Medical University, Lianyungang, dDepartment of Pathology, Affiliated Lianyungang Hospital of Xuzhou Medical University, Lianyungang, China

\section{Key Words}

$\mathrm{MARCH} 8 \cdot$ Gastric cancer $・$ Apoptosis $・$ PI3K pathway $•$ B-catenin stat3 pathway

\begin{abstract}
Background/Aims: To identify new treatment strategies for gastric cancer and to elucidate the mechanism underlying its pathophysiology, we transfected sh-MARCH8 into the human gastric cancer cell lines MKN-45 and AGS to investigate the roles of MARCH8 in gastric cancer. Methods: We used genetic engineering to construct the sh-MARCH8 interference plasmid and transfected it into gastric cancer cells. Colony formation assays and cell viability measurements were performed to detect the viability and proliferation of cancer cells. Wound healing assays were performed to estimate the migration and proliferation rates of the cells. Cell invasion assays were used to estimate the invasive abilities of the cells. Cell apoptosis analysis was performed by using flowing cytometry. Western blot analysis was performed to estimate the expression levels of proteins. Statistical analysis was performed using the SPSS 18.0 software. Student's t-test was used to determine the significance of all pairwise comparisons of interest. Results: We observed that the transfection of sh-MARCH8 inhibited the survival and proliferation of MKN-45 and AGS cells. The migration and invasion of the MKN-45 and AGS cells were significantly decreased, and apoptosis was induced in comparison with the control cells. These results were further confirmed by data showing that sh-MARCH8 increased the $\mathrm{BAX} / \mathrm{BCL} 2$ ratio in MKN-45 and AGS cells. We also observed that sh-MARCH8 inactivated the PI3K and B-catenin stat3 signaling pathways by changing protein expression levels or the phosphorylation of related proteins. Conclusion: These data suggested that sh-March8 reduced viability and induced apoptosis of the MKN-45 and AGS cells through the PI3K and B-catenin stat3 signaling pathways. Taken together, our data revealed that transfection of shMARCH8 into the MKN-45 and AGS gastric cancer cell lines inhibited their growth, and this approach may be useful as a novel strategy for gastric cancer therapy.

J. Yin, Z. Ji and Y. Hong contributed equally to this work.




\section{Cellular Physiology Cell Physiol Biochem 2018;49:306-321 \begin{tabular}{ll|l} 
DOI: 10.1159/000492882 & $\begin{array}{l}\text { O 2018 The Author(s). Published by S. Karger AG, Basel } \\
\text { www.karger.com/cpb }\end{array}$ \\
\hline
\end{tabular}}

Yin et al.: sh-MARCH8 Inhibits Gastric Cancer by PI3K

\section{Introduction}

Since researchers determined the genetic basis of cancer in 1914 [1], the carcinogenesis of many types of cancer has been studied, and the genetic theory of cancer has been accepted [2]. Gastric cancer (GC) is a highly heterogeneous disease with different molecular and genetic changes, including several chromosomal alterations $[3,4]$, variations in epigenetics [5-9], and miRNA involvement [10]. GC is the fifth most common cancer and the third most common cause of cancer deaths worldwide, accounting for $8.8 \%$ of all cancer-related deaths (723, 000 deaths) $[11,12]$. Even today, in east Asia, Latin America and eastern Europe, as well as specific subgroups in the United States, the incidence and mortality of gastric cancer remains disproportionately high $[11,12]$.

Over the past several decades, the study of GC has provided information on its genetics, epigenetic inheritance, transcriptome, and metabolic changes [13-18]. Based on Laurence's histopathological classification, a new molecular classification system was proposed to better classify gastric tumors [19-22].

The MARCH (membrane-associated RING-CH) family of E3 ubiquitin ligases was found with the aid of the viral protein homolog to interfere with host defenses [23]. Similar to most ubiquitin ligases, members of the MARCH family target various membrane proteins for degradation [24-27]. To date, eleven members of the MARCH family have been identified and characterized. Most of these ligases share a basic structure with c-MIR, the founding member of the family. Now known as MARCH8, this protein contains an N-terminal RING finger domain that potentially interacts with an E2 enzyme, as well as two trans-membrane domains $[23,25,28]$. These proteins usually contain several (two, four, or twelve) transmembrane (TM) domains; however, MARCH7 and MARCH10 do not contain any predicted TM domains [29].

The functions of MARCH8 and its close relative MARCH1 have been studied mostly in immune cells, where these proteins mediate the ubiquitination and downregulation of immune-regulatory cell surface molecules, including MHC-II, Fas, and CD86 (B7.2) [24, 25, 30-33]. MARCH8 also controls cell surface expression of some additional proteins [34, 35]. It has been observed that MARCH8 is expressed in the early embryos of zebrafish and Xenopus, suggesting that this protein might have a role in embryogenesis [37]. MARCH1 may be involved in dendritic cell maturation by promoting the ubiquitination and degradation of MHC-II and CD86 [29, 32, 38, 39]. MARCH10 and MARCH11 are highly expressed in the testes and are predicted to play a pivotal role in spermatogenesis and the organization of spermatid flagella [40-42]. Several other MARCH family members are widely expressed in various tissues, but their physiological roles are largely unknown.

In the present study, we aimed to investigate the roles of MARCH8 in human GC and to elucidate the underlying mechanisms. In this study, we report that knockdown of MARCH8 reduced viability and induced apoptosis in MKN-45 and AGS cells through the PI3K and ß-catenin stat3 signaling pathways. These data suggest that MARCH8 inhibition may be a novel strategy for gastric cancer therapy.

\section{Materials and Methods}

\section{Agents}

The RPMI-1640 medium was from HyClone Company (Cat" SH30809.1, Logan, Utah, USA). The fetal goat serum was from Gibco (Cat" A31608-02,USA). The antibiotics, 0.25\% trypsin, CCK-8 and DMSO were from Beijing Solarbio Science and Technology Company (Cat ${ }^{\#}$ P1400, T1300, CA1210, D8370, Beijing, China). Lipofectamine2000 was obtained from Invitrogen (Cat ${ }^{\#}$ 1777190, USA). The Annexin V-FITC/PI Apoptosis Kit was ordered from the 4A Biotech Company (Cat ${ }^{\#}$ FXP018-100, Beijing, China). The primary antibodies, including AKT CST (Cat ${ }^{\#}$ 9272, 1:1000); p-AKT CST (Cat" 4060, 1:1000); mTOR CST (Cat" 2972, 


\section{Cellular Physiology Cell Physiol Biochem 2018;49:306-321 \begin{tabular}{l|l|l} 
and Biochemistry 10.1159/000492882 & $\begin{array}{l}\text { C) 2018 The Author(s). Published by S. Karger AG, Basel } \\
\text { www.karger.com/cpb }\end{array}$
\end{tabular}}

Yin et al.: sh-MARCH8 Inhibits Gastric Cancer by PI3K

1:1000); p-mTOR CST (Cat ${ }^{\#}$ 5536, 1:1000); BCL2 Abcam (Cat ${ }^{\#}$ ab692, 1:1000); BAX Abcam (Cat ${ }^{\#}$ ab32503, 1:1000); active-caspase-3 Abcam (Cat" ab13585, 1:1000); $\beta$-catenin PTG (Cat" ${ }^{\#}$ 51067-2-AP, 1:1000); E-CAD PTG (Cat ${ }^{\#}$ 20874-1-AP, 1:1000); CYDLIN D1 Abcam (Cat" ab40754, 1:1000); P-STAT3 Abcam (Cat" ab30647, 1:1000); GAPDH PTG (Cat" 60004-1-Ig, 1:5000); and all rabbit anti-human antibodies were from Abcam (Cambridge, United Kingdom). The HRP sheep anti-rabbit/mouse secondary antibodies (1:5000) were from PTG (USA).

The ultrapure RNA extraction kit (HiFiScript cDNA Synthesis Kit), fluorescence quantitative PCR kit (UltraSYBR Mixture), RIPA lysis buffer, BCA protein assay kit, and protease inhibitor cocktail were all from Beijing Kangwei Century Company (CwBio, Beijing, China). Additionally, the primers were synthesized by Genewiz (Beijing, China). The Matrigel was from BD Biosciences (354230, USA), and the Transwell cell culture plates were from Millipore (M160439, USA). The cell culture equipment was from Eppendorf (Hamburg, Germany). The LDS sample buffer was from Invitrogen (NP0007, USA). The protein marker was from ThermoScientific (SM1881, USA), and the ECL developer was from PTG (B500022, USA).

\section{Construction of sh-MARCH8 interference plasmid}

The MARCH8 interference sequence is $5^{\prime}$-CTTGAGCTGAATGAGAGAATA- ${ }^{\prime}$. For insertion into the p-Super vector, $B g l$ II and Hind III restriction enzyme sites were fused to each terminus. The plasmid containing the MARCH8 interference sequence was confirmed by enzyme digestion and sequencing.

\section{Cell culture and transfection}

The MKN-45 and AGS gastric cancer cell lines were purchased from the cell bank of the Chinese Academy of Sciences (Shanghai, China). The cells were incubated in RPMI-1640 medium containing $10 \%$ FBS, $100 \mathrm{U} / \mathrm{ml}$ penicillin and $0.1 \mathrm{mg} / \mathrm{ml}$ streptomycin at $37^{\circ} \mathrm{C}$ with $5 \% \mathrm{CO}_{2}$. The cells were trypsinized during the logarithmic phase and were re-plated into a fresh 6-well plate. The sh-MARCH8 transfection was performed using Lipofectamine2000 following the manufacturer's instructions. The p-Super empty vector was used as the control.

\section{Fluorescence quantitative PCR}

The total RNA was extracted using the Ultrapure RNA Extraction Kit, and the cDNA was synthesized with the HiFiScript cDNA Synthesis Kit. The expression of MARCH8 was detected by fluorescence quantitative PCR, and the primers used are listed below:

\section{MARCH8:}

Forward: 5'-GGGAGAAGTTGCAGATGAC-3'

Reverse: 5'-GCACATACAAGGACCAGAC-3'

$\beta$-actin was used as standard control:

Forward: 5'-CCCGAGCCGTGTTTCCT-3'

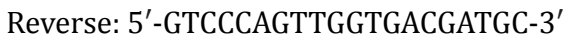

The relative expression was calculated using the $2^{-\Delta \Delta C t}$ method.

\section{Western blot analysis}

The transfected cells were cultured in a 6-well plate to $95 \%$ confluence. Forty-eight hours after transfection, the cells were lysed with ice-cold RIPA buffer (150 mM NaCl, 1.0\% NP-40, 0.1\% Triton X-100, $0.5 \%$ sodium deoxycholate, $0.1 \%$ SDS, $50 \mathrm{mM}$ Tris- $\mathrm{HCl}, \mathrm{pH} 8.0$ and protease inhibitors), and the protein concentration was measured using the BCA method. The protein samples were denatured by heating at $95^{\circ} \mathrm{C}$ for 5 minutes, and approximately $20 \mu \mathrm{g}$ was loaded into each lane in a 10\% SDS-PAGE gel. After transferring the protein to the PVDF membrane, it was blocked with $5 \%$ non-fat milk for 1 hour at room temperature and incubated with primary antibodies in blocking solution at $4^{\circ} \mathrm{C}$ overnight. The membrane was then washed three times for 5 minutes with TBST and was later incubated with the relevant secondary antibody in blocking buffer at room temperature for 1 hour. After washing, the membrane was covered with the ECL substrate for signal development. The images were acquired using darkroom development techniques for chemiluminescence. 


\section{Cellular Physiology Cell Physiol Biochem 2018:49:306-321 \begin{tabular}{l|l|l} 
and Biochemistry & Dublished online: 23 August, 2018 & $\begin{array}{l}\text { C } 2018 \text { The Author(s). Published by S. Karger AG, Basel } \\
\text { www.karger.com/cpb }\end{array}$
\end{tabular}}

Yin et al.: sh-MARCH8 Inhibits Gastric Cancer by PI3K

\section{Cell viability and proliferation assays}

After transfection for $24 \mathrm{~h}$, the cells were trypsinized and counted to make a suspension. Approximately 1000 cells were seeded into each well of a 96 -well plate. Cell viability was checked every 24 hours by adding $10 \mu \mathrm{l}$ of CCK8 reagent. After incubation at $37^{\circ} \mathrm{C}$ for 90 minutes, an OD value of excitation light was detected using enzyme standard instrument with $450 \mathrm{~nm}$. A proliferation curve was plotted using the OD values.

\section{Colony formation assays}

After transfection for $24 \mathrm{~h}$, the cells were trypsinized to produce a single-cell suspension and were counted. Approximately 500 cells were seeded into each $10 \mathrm{~cm}$ dish with $5 \mathrm{ml}$ of medium. The dishes were placed in an incubator at $37^{\circ} \mathrm{C}$ with $5 \% \mathrm{CO}_{2}$ and left there until the cells formed sufficiently large clones. The medium was removed, and the cells were rinsed carefully with PBS. The cells were then fixed with $5 \mathrm{ml} 4 \%$ paraformaldehyde for 30 minutes followed by staining with $0.1 \%$ crystal violet for 30 minutes. The crystal violet was carefully removed followed by rinsing with tap water. The dishes with the colonies were left to dry in normal air at room temperature. The numbers of colonies were counted and compared to the control group.

\section{Wound healing assays}

Wound healing assays were carried out to estimate the migration and proliferation rates of the cells. The cells were plated in a 6 -well plate at $5 \times 10^{5}$ cells per well and incubated at $37{ }^{\circ} \mathrm{C}$ overnight to obtain a $100 \%$ confluent cell monolayer. Twenty-four hours after incubation, a line was scratched with a pipette tip to destroy a small area of the cell layer. After washing with PBS, the cells were incubated in a serum-free medium. The open gaps were later examined using a microscope over a time range of 0,24 or 48 hours, and the sizes of the gaps were measured with ImageJ software at 6 to 8 different points.

\section{Cell invasion assays}

A coating buffer (containing $0.01 \mathrm{M}$ Tris $\mathrm{pH} 8.0,0.7 \% \mathrm{NaCl}$ and filtered through a $0.2-\mu \mathrm{m}$ sterile filter unit) was prepared before the experiment. Any pipettes, syringes, or containers that came into contact with the Matrigel were chilled prior to use. The aliquot of the Matrigel matrix was placed on ice at $4^{\circ} \mathrm{C}$ overnight. The Matrigel was subsequently diluted with serum-free 1640 medium at a 1:6 ratio, and $100 \mu \mathrm{l}$ were applied to each permeable support well of a 24 -well plate. This plate was incubated at $37^{\circ} \mathrm{C}$ for 4 hours. The remaining coating buffer was removed from the permeable support membrane without disturbing the Matrigel layer. Next, $100 \mu \mathrm{l}$ and $600 \mu \mathrm{l}$ of serum-free 1640 medium were added to the inside and outside of the support well, respectively, followed by incubation at $37^{\circ} \mathrm{C}$ for 30 minutes. The coated invasion chambers were then ready for use. The cells were trypsinized and re-suspended in serum-free culture medium. After that step, $100 \mu \mathrm{l}$ of the cell suspension (containing $1 \times 10^{4}$ cells) was added to each of the 24 -well invasion chambers and $600 \mu \mathrm{l}$ of medium containing $10 \%$ FBS was added to the outside of the chamber.

Twenty-four hours after incubation at $37^{\circ} \mathrm{C}$, the non-invading cells were removed using a cotton swab and both sides of the chambers were washed twice with 1X PBS. The cells were fixed with $4 \%$ paraformaldehyde at room temperature for 15 minutes and stained with $0.1 \%$ crystal violet for 5 minutes. After washing with 1X PBS, the filters were cut off and mounted on slides. The cells were observed and imaged, and the numbers of invaded cells were counted under a microscope.

\section{Flow cytometric analysis of cell apoptosis}

After 24 more hours of incubation in serum-free medium for starvation, the cells were trypsinized with EDTA-free trypsin. After washing with PBS, the cells were re-suspended in 1X binding buffer (10 mM HEPES/NaOH [pH 7.4], $140 \mathrm{mM} \mathrm{NaCl}, 2.5 \mathrm{mM} \mathrm{CaCl}_{2}$ ). The cell density was adjusted to $35 \mathrm{x} 10^{5} \mathrm{cells} / \mathrm{ml}$. After that step, $5 \mu \mathrm{l}$ of Annexin V-FITC solution was added to the $100 \mu \mathrm{l}$ of cell suspension and incubated at room temperature in the dark. Next, $10 \mu \mathrm{l}$ of $20 \mu \mathrm{g} / \mathrm{ml}$ propidium iodide (PI) was added for two more minutes of double staining. The results were analyzed with a flow cytometer (BD FACSC anto II, BD Biosciences, San Jose, CA, USA). The viable cells were negative for both PI and Annexin V, while the apoptotic cells were positive for Annexin V and negative for PI. Late apoptotic cells showed both Annexin V and PI positivity. The apoptotic rate was calculated using the BD FACSDiva software. 


\section{Cellular Physiology Cell Physiol Biochem 2018;49:306-321 \begin{tabular}{ll|l} 
and Biochemistry & $\begin{array}{l}\text { DOI: 10.1159/000492882 } \\
\text { Published online: 23 August, } 2018\end{array}$ & $\begin{array}{l}\text { (c) } 2018 \text { The Author(s). Published by S. Karger AG, Basel } \\
\text { www.karger.com/cpb }\end{array}$
\end{tabular}}

Yin et al.: sh-MARCH8 Inhibits Gastric Cancer by PI3K

\section{Immunohistochemical analysis}

An EliVisionTMplus kit (KIT-9902) was used for the immunohistochemical analysis. The tissue sections were dewaxed using xylene and rehydrated with an ethanol gradient. Antigen retrieval was completed by boiling the sections two times in sodium citrate for 10 minutes. The slides were treated with $3 \% \mathrm{H}_{2} \mathrm{O}_{2}$ for 10 minutes followed by washing with TBS. After blocking for 1 hour at room temperature, primary antibodies were applied to the sections, and they were incubated for 1 hour at room temperature. The slides were developed with DAB developer and doubled stained with hematoxylin, dehydrated with gradient ethanol and mounted with neutral resins. The slides were examined under an OPTIKA B-150 microscope and the images were analyzed with Image Pro Plus6.0 (Media Cybernetics).

Under the 40X objective, 3-5 fields of view were randomly chosen. The staining was scored as A: 0 for no staining, 1 for light yellow, 2 for light brown, and 3 for dark brown. The ratios of the stained cells were scored as B: 1 for $1 \%-10 \%, 2$ for $11 \%-50 \%$, 3 for $51 \%-80 \%$, and 4 for over $80 \%$. The final score was calculated by multiplying A x B. A score of 0 would be considered negative, 1-4 as light positive and over 4 as strong positive.

\section{Statistical analysis}

The statistical analysis was completed using the SPSS 18.0 software. The results were expressed as means \pm standard deviations (SD), as indicated in the figure legend. The data are representative of three independent experiments performed in triplicate. Student's t-test was used to determine the significance for all pairwise comparisons of interest. The differences were considered to be statistically significant when $P<0.05$.

\section{Results}

MARCH8 expression in gastric cancer

MARCH8 was reported to mediate the ubiquitination and downregulation of immune regulatory cell surface molecules in immune cells $[24,25,30-33]$ and to control cell surface expression of some additional proteins [34, 35]. We looked up the expression of MARCH8 in the online tool Gene Expression Profiling Interactive Analysis (GEPIA), which is based on the Cancer Genome Atlas (TCGA) and the Genotype-Tissue Expression (GTEx) dataset for transcriptomic analysis [36], which includes 408 GC samples and 211 controls. As shown in Fig. 1, the expression level of MARCH8 is significantly higher in GC samples at $P<0.05$. This observation suggests the possibility that MARCH8 is involved in the tumorigenesis of GC and is a potentially good candidate for GC treatment.

MARCH8 could be used as a prognostic marker in gastric cancer

The online Kaplan-Meier plotter (www.kmplot.com) can assess the survival effect of a gene or a combination of genes in lung, breast, ovarian and gastric cancer. Gene expression data and relapse-free and

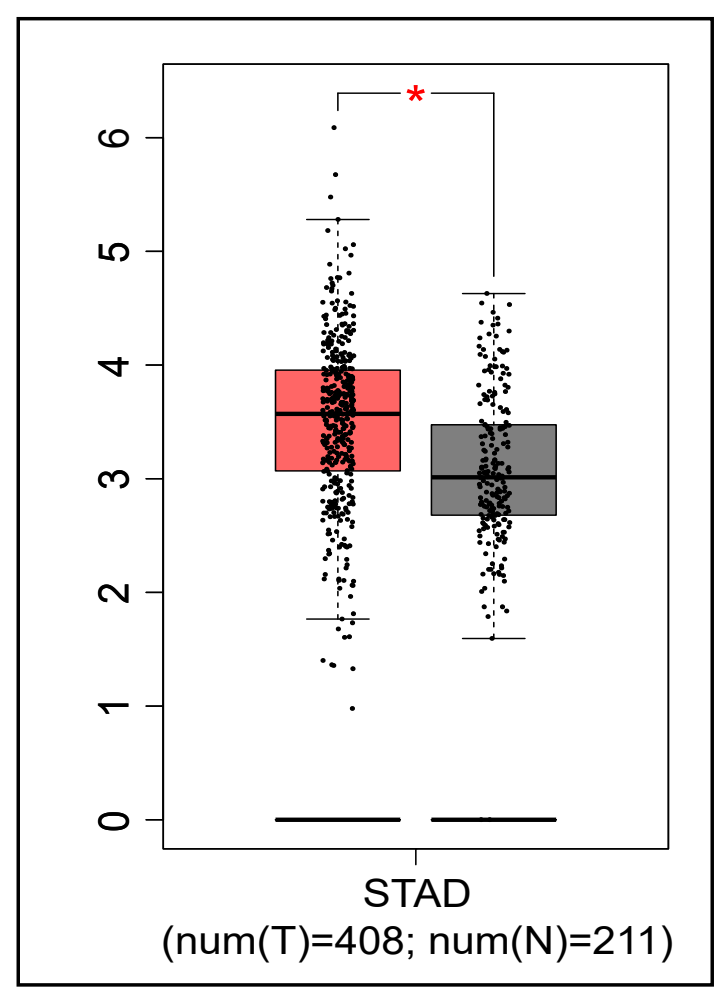

Fig. 1. Boxplot of the mRNA expression levels of MARCH8 in gastric cancer and controls. The red and gray boxes represent gastric cancer and normal tissues, respectively. The data were obtained from the TCGA database, including 408 gastric cancer samples and 211 controls. The y-axis indicates the $\log _{2}$-transformed gene expression levels. 


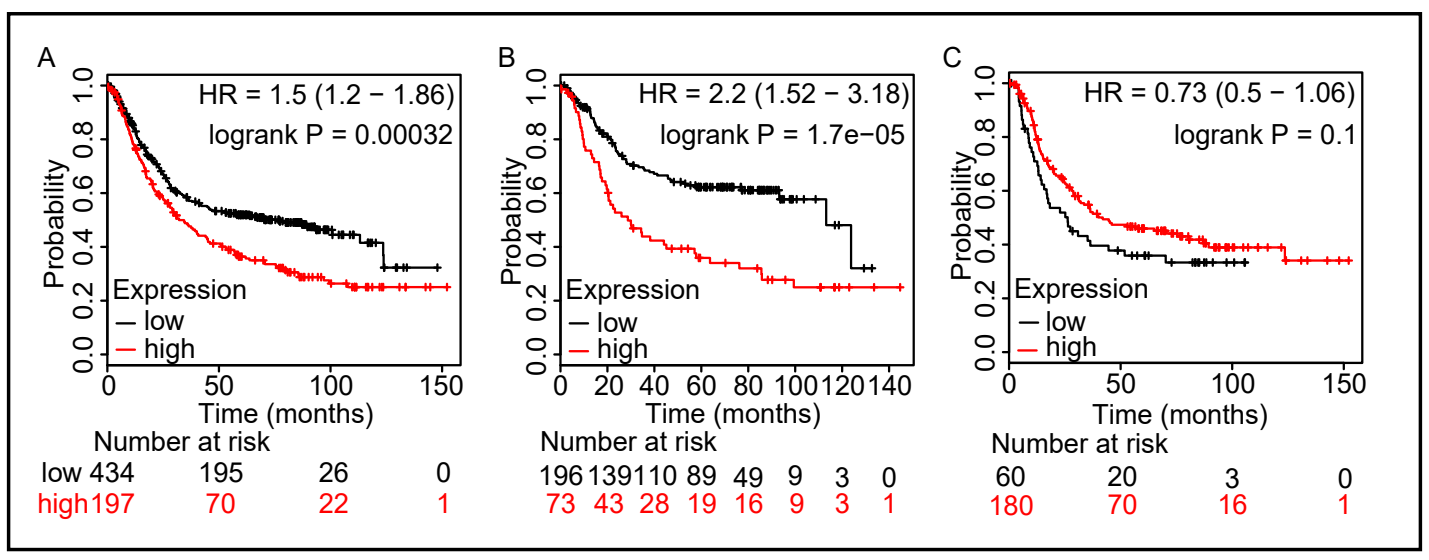

Fig. 2. Survival probability of the gastric cancer patients with high and low MARCH8 mRNA expression levels. The data were obtained from www.kmplot.com. (A) Survival curves are plotted for all gastric cancer patients $(n=876)$. (B) Survival curves are plotted for intestinal-type cancer patients $(n=320)$. (C) Survival curves are plotted for diffuse-type cancer patients $(n=241)$.

Table 1. The correlation of MARCH8 mRNA expression with clinical factors in gastric cancer patients.

\begin{tabular}{llllll}
\hline Sample information & & Cases & HR & 95\% CI & P \\
\hline \multirow{2}{*}{ HER status } & negative & 641 & 1.53 & $1.17-2$ & 0.0017 \\
& positive & 425 & 1.65 & $1.13-2.39$ & 0.0082 \\
pathological grades & I & 166 & 1.39 & $0.86-2.24$ & 0.18 \\
& II & 67 & 1.49 & $0.77-2.87$ & 0.23 \\
\multirow{5}{*}{ clinical stages } & 1 & 69 & 1.81 & $0.58-5.64$ & 0.3 \\
& 2 & 145 & 2.04 & $1.1-3.8$ & 0.021 \\
& 3 & 319 & 1.64 & $1.12-2.4$ & 0.01 \\
\multirow{2}{*}{ Treatment } & 4 & 152 & 1.59 & $1.06-2.38$ & 0.025 \\
& surgery alone & 393 & 1.45 & $1.08-1.95$ & 0.013 \\
& 5-FU-based adjuvant & 158 & 0.65 & $0.21-1.96$ & 0.44 \\
& other adjuvant & 80 & 0.33 & $0.13-0.79$ & 0.0086 \\
\hline
\end{tabular}

overall survival information were downloaded from the GEO (Affymetrix microarrays only), EGA and TCGA databases. The effect of MARCH8 mRNA expression on the survival of GC patients was determined using the Kaplan-Meier plotter; 876 GC samples were included, of which there were 320 intestinal-type cancer samples and 241 diffuse-type cancer samples with 33 months of follow-up. The valid Affymetrix ID of MARCH8 is 231933_at. The KaplanMeier survival curves for the low and high MARCH8 expression patient groups are shown in Fig. 2. The plots showed poorer prognosis rates for the GC (HR=1.5, 95\%CI 1.2-1.86, $P=0.00032$ ) and intestinal-type GC patients (HR=2.2, 95\%CI 1.52-3.18, $P=1.7 \mathrm{e}-5)$ with higher MARCH8 expression.

The correlation of MARCH8 expression with various clinical factors was analyzed, including clinical stage, HER2 status, pathological grade and treatment method (Table 1). The MARCH8 mRNA expression level is significantly correlated with HER2 status, clinical stage, and surgery treatment at $\mathrm{P}<0.05$.

\section{Expression of MARCH8 is remarkably increased in gastric cancer tissues}

We first detected the endogenous level of MARCH8 in para-carcinoma tissues and GC tissue samples obtained from the same patient using a tissue microarray. There is strong immunohistochemical staining of MARCH8 in GC tissue, while its expression is considerably lower in normal tissues (Fig. 3). The correlation of MARCH8 expression and the relationship 
Fig. 3. Endogenous levels of MARCH8 in para-carcinoma tissues and gastric cancer tissues were detected by tissue microarray. (A) MARCH8 expression in the tissue adjacent to carcinoma in patients with gastric cancer (100); (B) MARCH8 expression in cancer tissue in patients with gastric cancer (100); (C) MARCH8 expression in the tissue adjacent to the carcinoma in patients with gastric cancer (400); (D) MARCH8 expression in cancer tissue in patients with gastric cancer (400).

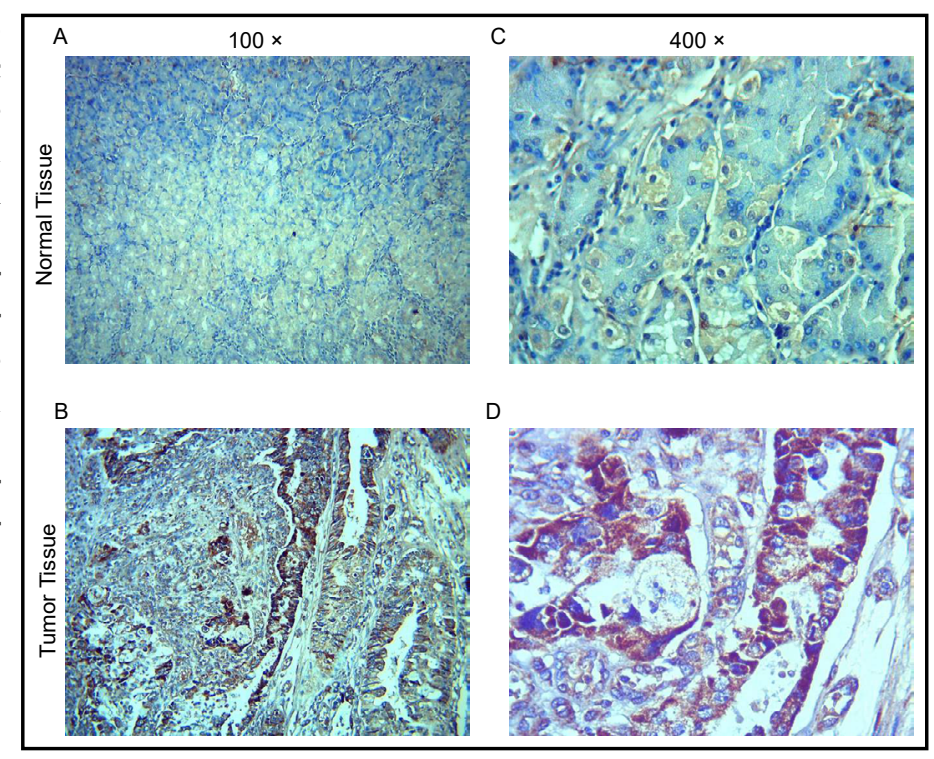

Table 2. MARCH8 expression and the relationship between clinical pathological features of gastric cancer patients. * In some cases, the clinical pathological information is not complete, so the total cases of lymphnode metastasis and pathological grade was less than 31 cases, but no influence on the reliability of the experimental results

\begin{tabular}{|c|c|c|c|c|}
\hline Clinicopathologic feature & $\begin{array}{l}\text { Cases } \\
\text { (n) }\end{array}$ & $\begin{array}{l}\text { MARCH8 level } \\
\text { High-expression } \\
\text { (n) }\end{array}$ & $\begin{array}{l}\text { Low-expression } \\
\text { (n) }\end{array}$ & $P$ \\
\hline \multicolumn{5}{|c|}{ 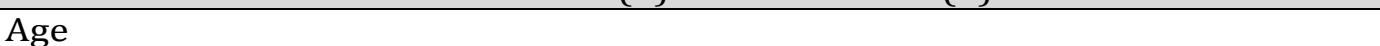 } \\
\hline$\leq 60$ & 17 & 7 & 10 & \multirow{2}{*}{0.2001} \\
\hline$>60$ & 14 & 9 & 5 & \\
\hline \multicolumn{5}{|l|}{ Sex } \\
\hline Male & 18 & 9 & 9 & \multirow{2}{*}{0.654} \\
\hline Female & 13 & 7 & 5 & \\
\hline \multicolumn{5}{|l|}{ Tumor sizes } \\
\hline$\leq 5 \mathrm{~cm}$ & 20 & 7 & 13 & \multirow{2}{*}{0.0285} \\
\hline$>5 \mathrm{~cm}$ & 11 & 9 & 3 & \\
\hline \multicolumn{5}{|l|}{ Lymph-node metastasis* } \\
\hline With & 13 & 7 & 6 & \multirow{2}{*}{0.8548} \\
\hline Without & 10 & 5 & 5 & \\
\hline \multicolumn{5}{|l|}{ Pathological grade* } \\
\hline I - II & 11 & 8 & 3 & \multirow{2}{*}{0.1333} \\
\hline III & 12 & 5 & 7 & \\
\hline
\end{tabular}

between the clinical pathological features of GC patients were analyzed and listed in Table 2 . MARCH8 expression is significantly higher in patients with tumors greater than $5 \mathrm{~cm}$ than in patients with tumors less than or equal to $5 \mathrm{~cm}(\mathrm{P}=0.0285)$.

Transfection of the sh-MARCH8 plasmid efficiently inhibited the expression of MARCH8 in $M K N-45$ and $A G S$ cells

The efficiency of the MARCH8 knockdown by the p-Super sh-MARCH8 plasmid was determined in two GC cell lines, MKN-45 and AGS. The MARCH8 RNA levels in both shMARCH8-transfected cell lines were significantly reduced (Fig. 4 A). Accordingly, the protein levels in both cell lines were decreased, as demonstrated by the protein band intensities (Fig. 4 B, left), which were standardized to GAPDH as shown in the bar graph (Fig. 4 B, right).

\section{KARGER}




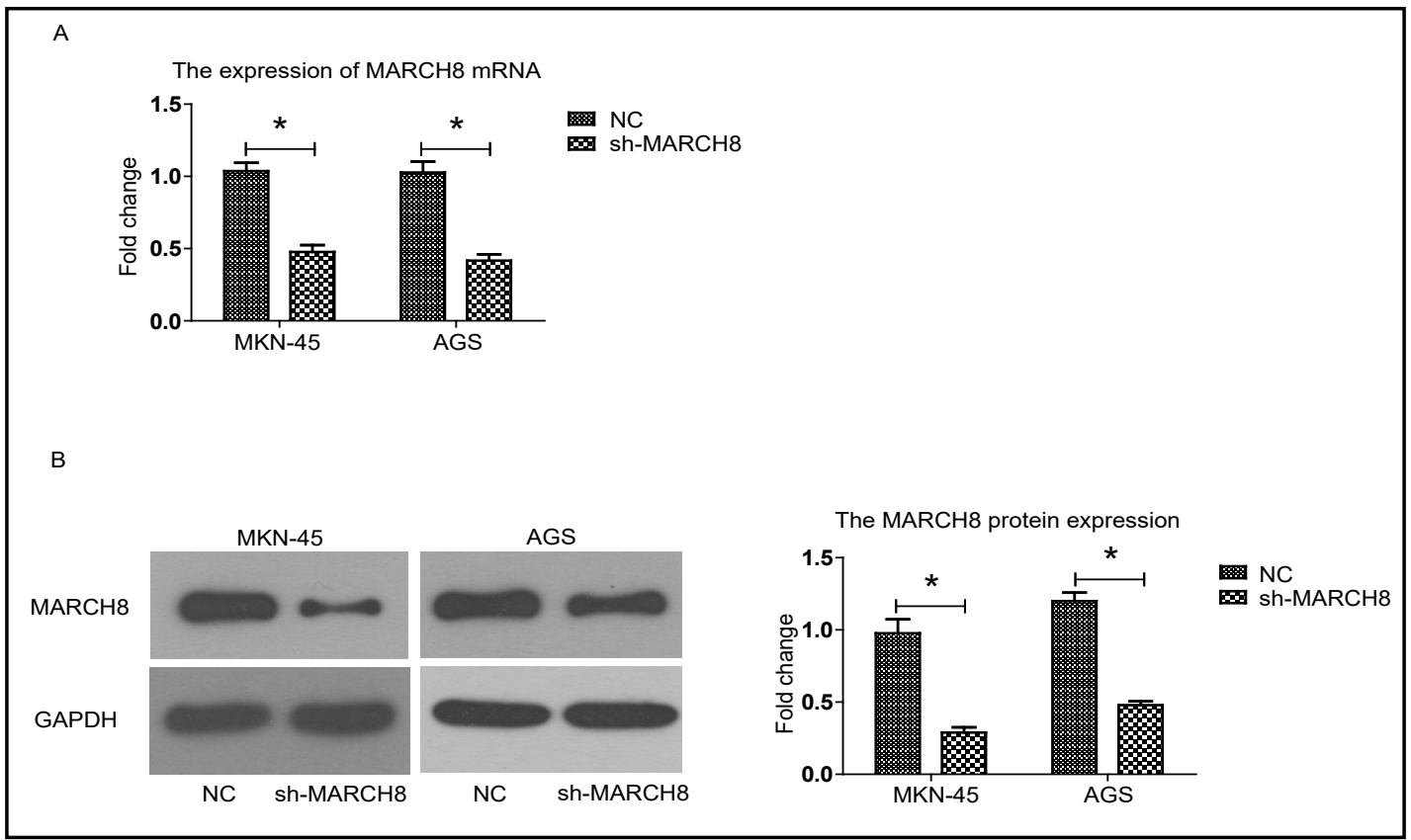

Fig. 4. Sh-MARCH8 plasmid can inhibit MARCH8 expression in MKN-45 and AGS cells. (A) The expression of MARCH8 mRNA in sh-MARCH8-transfected MKN-45 and AGS cells was detected by quantitative PCR. (B) The protein levels of MARCH8 in both cell lines were detected by Western blot analysis (left) and were standardized to GAPDH (right).

\section{Reduction of MARCH8 significantly inhibited gastric cancer cell proliferation}

As sh-MARCH8 efficiently decreases the expression of MARCH8, we next measured the effect of MARCH8 knockdown on the proliferation of the MKN-45 and AGS GC cells. CCK8 assays and colony formation assays were performed to evaluate whether the reduction of MARCH8 may affect the proliferation of MKN-45 and AGS cells. As shown by the CCK8 assays, MARCH8 knockdown significantly decreased the viability of both MKN-45 and AGS cells (Fig. $5 \mathrm{~A}$ and $\mathrm{B}$ ). Also, the colony formation assays showed that transfection of the sh-MARCH8 vector resulted in decreased proliferation of both MKN-45 and AGS cells in comparison to the si-NC transfection control (Fig. 5 C and D).

Knockdown of MARCH8 inhibited migration and invasion of MKN-45 and AGS cells

Transwell assays were performed to investigate the effect of MARCH8 knockdown on cancer cell migration and invasion in vitro. The migration and invasion assays provide an in vitro system to study cell invasion by malignant and normal cells. The numbers of crystal violet-stained cells in sh-MARCH8-transfected wells are considerably lower than those of the control groups (Fig. $5 \mathrm{E}$ and F). The numbers of migrated cells and invasive cells were significantly decreased in the sh-MARCH8-transfected wells for both the MKN-45 and AGS cells (Fig. $5 \mathrm{G}$ and $\mathrm{H}$ ).

Down-regulation of MARCH8 induced apoptosis of gastric cancer cells and affected the expression of apoptosis-related proteins

GC cell apoptosis was analyzed by flow cytometry. The cells were transfected with the sh-MARCH8 plasmid or the control plasmid (sh-RNA) for 48 hours and later double stained with Annexin V and PI. Early apoptotic cells were identified by Annexin V-positive and PInegative staining. Late apoptotic cells were positively stained by both dyes. The transfection of sh-MARCH8 significantly increased the rate of apoptosis of both the MKN-45 and AGS cells compared with the control cells (Fig. 6 A and B). 


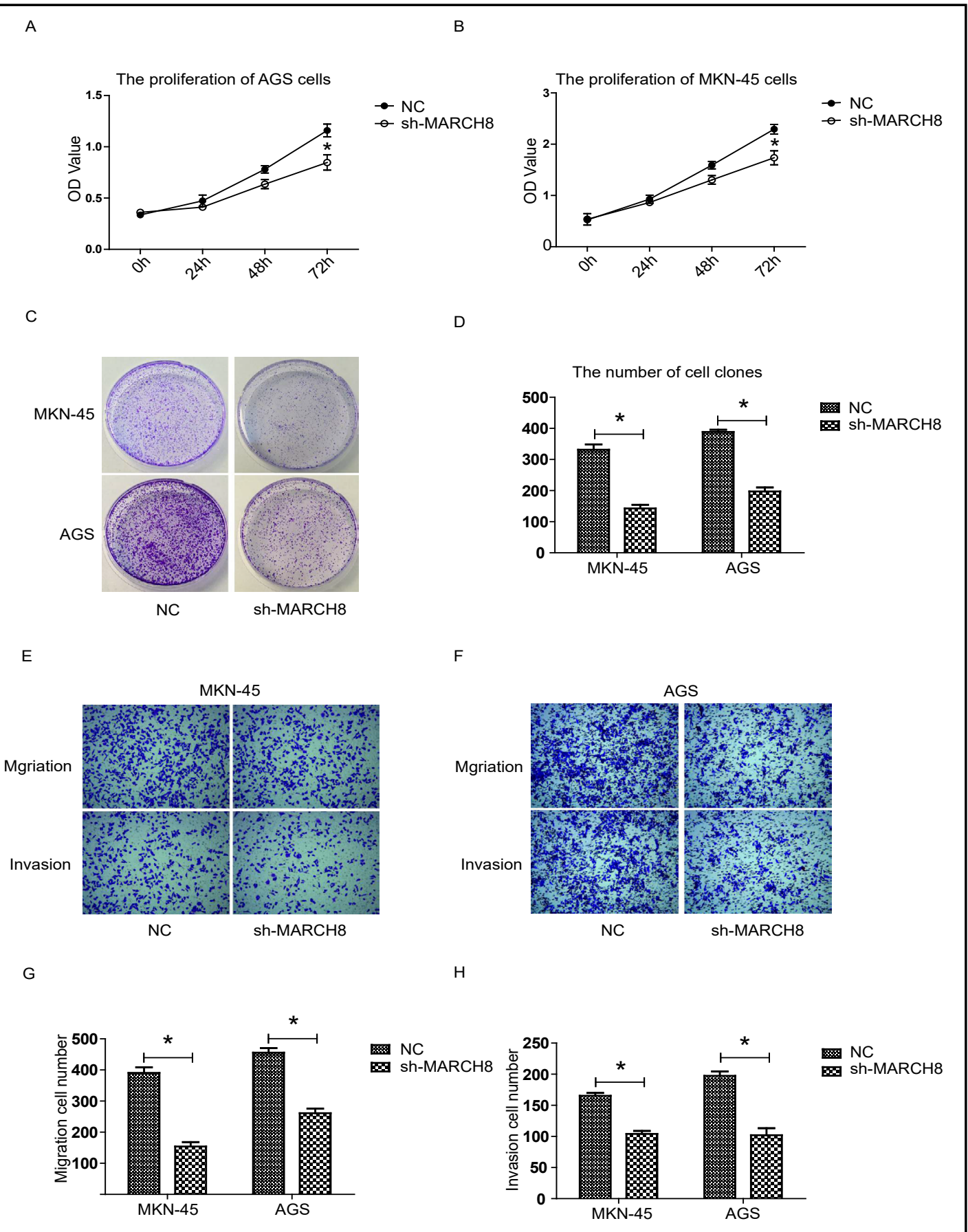

Fig. 5. Down-regulation of MARCH8 significantly inhibited cell proliferation, migration and invasion in gastric cancer. (A) and (B) The time curves showed that the proliferation of both MKN-45 and AGS cells was decreased after MARCH8 knockdown. (C) The viability of the MKN-45 and AGS cells and (D) the cologenic ability. (D) The influence of MARCH8 on clone numbers was evaluated by a clone formation efficiency assay. The error bars indicate \pm SDs. ${ }^{*} \mathrm{P}<0.01$ by Student's t-test. (E) and (F) Crystal violet-stained cells show the migration and invasion of cells transfected with sh-MARCH8 and the corresponding sh-NC control. (G) and (H) The numbers of migrating and invading cells were significantly decreased in sh-MARCH8-transfected MKN-45 and AGS cells $(\mathrm{P}<0.01)$. 


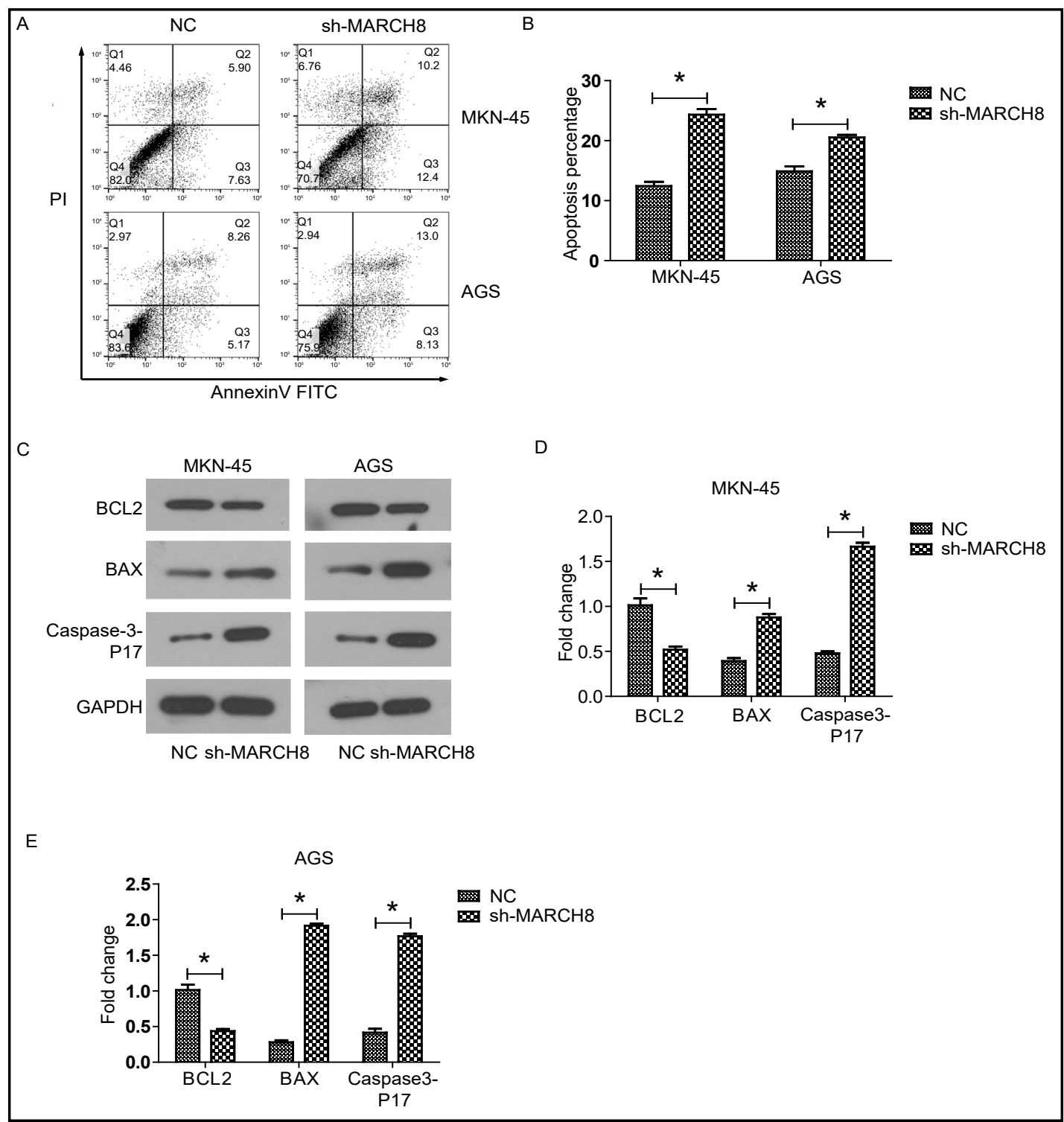

Fig. 6. sh-MARCH8 induced apoptosis of gastric cancer cells and affected the expression of apoptosis-related proteins. (A) MKN-45 (upper) and AGS (lower) cells were harvested and stained with Annexin V-fluorescein isothiocyanate (FITC) and PI, and cell apoptosis was analyzed by flow cytometry. Flow cytometry staining revealed a significant shift in Annexin V-FITC-positive cells in the sh-MARCH8 transfected cells. (B) The percentage of apoptotic cells was significantly increased by sh-MARCH8 ( $\left.{ }^{*} \mathrm{P}<0.01\right)$. (C) MKN-45 (left) and AGS (right) cell lysates were separated by SDS-PAGE and analyzed by Western blotting with the indicated antibodies. GAPDH was used as a loading control. (D and E) The values of the band intensities represented the densitometric estimation of each band normalized to GAPDH $\left({ }^{*} \mathrm{P}<0.01\right)$.

To determine the mechanism of apoptosis induction by sh-MARCH8, a Western blot analysis was performed. As previous studies have shown that the expression of the anti-apoptotic BCL2 and pro-apoptotic BAX proteins are critical factors for initiating apoptosis via the mitochondria [43, 44], we examined the expression of BCL2 and BAX in the sh-MARCH8 plasmid-transfected MKN-45 and AGS cells by Western blot analysis. Compared with the control group, the sh-MARCH8-transfection decreased BCL2 expression while simultaneously increasing BAX expression (Fig. 6 C, D and E). These results indicated that sh-MARCH8 increased the BAX/BCL2 ratio in gastric cancer cells and suggested that MARCH8 knockdown may trigger the mitochondrial apoptotic pathway in these cells. Next, KARGER 
we measured the expression levels of caspase- 3 p17 and showed that transfection of shMARCH8 robustly increased the expression of caspase-3 p17 (Fig. 6 C, D and E).

sh-MARCH8 suppressed the activation of the PI3K and $\beta$-catenin stat 3 signaling pathways in gastric cancer cells

To elucidate the molecular mechanism of sh-MARCH8 on GC inhibition, we examined the effect of sh-MARCH8 on the PI3K pathway in both MKN-45 and AGS cells. The PI3K pathway is implicated in many cellular processes including cell growth, survival, and the promotion of angiogenesis. After being activated at the cell membrane, PI3K phosphorylates PIP2, leading to an accumulation of PIP3 [45]. This lipid second messenger recruits AKT and PDK1 to the cell membrane, where AKT is phosphorylated by PDK1 [46]. Phosphorylated AKT regulates cellular processes by phosphorylation of a number of substrates, including BclxL/ BCL2-associated death promoter (BAD) [47]. Another AKT substrate, mTOR, has the most significant role in tumorigenesis [48]. Once activated, mTOR increases mRNA translation by phosphorylation of the downstream molecule P70-S6 kinase [49]. The PI3K-AKT-mTOR pathway can be negatively regulated by the tumor suppressor PTEN [50].

Our results showed that in the sh-MARCH8-transfected group, there was no change in the expression of AKT; however, the level of the phosphorylated form p-AKT decreased (Fig. 7 A, C and D). mTOR has the same expression pattern as AKT (Fig. 7 A, C and D). These data suggested that MARCH8 knockdown inhibited PI3K and caused the decreases in the

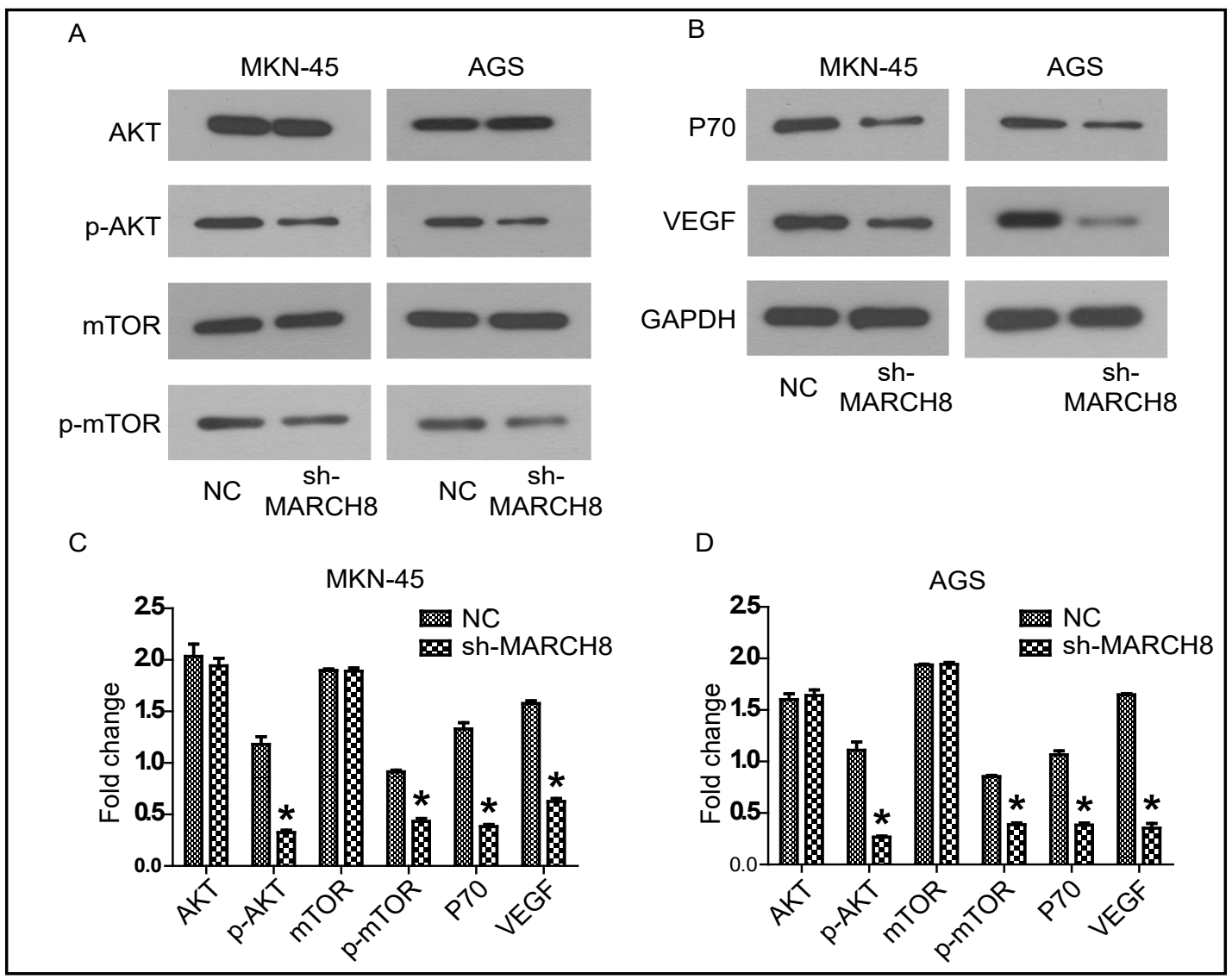

Fig. 7. sh-MARCH8 suppressed the activation of the PI3K signaling pathway in gastric cancer cells. (A) and (B) MKN-45 (left) and AGS (right) cell lysates were separated by SDS-PAGE and analyzed by Western blotting with the indicated antibodies. GAPDH was used as a loading control. (C) and (D) The values of the band intensities represented the densitometric estimation of each band normalized to GAPDH from the MKN-45 (C) and AGS (D) cells ( $\left.{ }^{*} \mathrm{P}<0.01\right)$.

\section{KARGER}




\section{Cellular Physiology Cell Physiol Biochem 2018;49:306-321

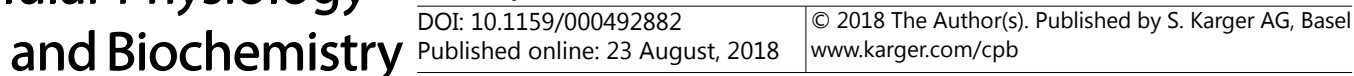 \\ Yin et al.: sh-MARCH8 Inhibits Gastric Cancer by PI3K}

phosphorylated forms of AKT and mTOR. The expression levels of P70 and VEGF were also decreased after transfection of sh-MARCH8 (Fig. 7 B, C and D).

To further confirm this conclusion, we examined the effect of sh-MARCH8 on the expression levels of members of the $ß$-catenin stat 3 signaling pathway, including ß-catenin, E-cadherin, Cyclin D1 and p-STAT3. Our results showed increased expression of E-cadherin and decreased expression of $ß$-catenin, Cyclin D1 and p-STAT3 (Fig. 8). The decreased Cyclin D1 expression in the sh-MARCH8-treated group was consistent with AKT inhibition and mTOR phosphorylation. Since PI3K activation inhibits GSK3 $\beta$, the increased expression of GSK3 $\beta$ suggested that the PI3K expression was inhibited by shMARCH8 transfection.

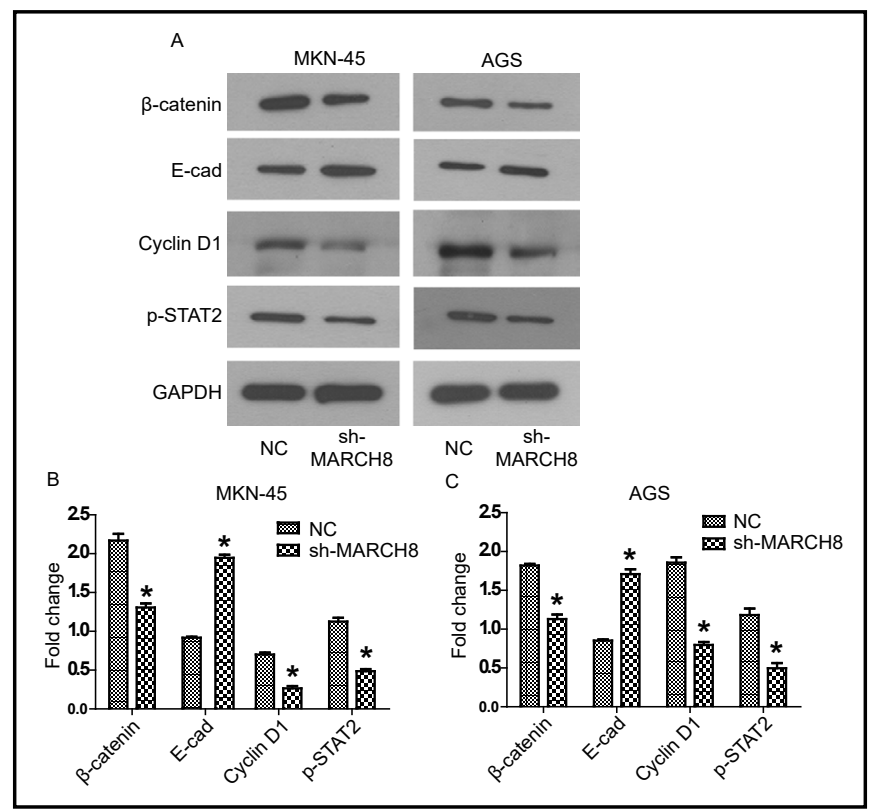

Fig. 8. sh-MARCH8 inhibited the activation of the $\beta$-catenin stat3 signaling pathway in gastric cancer cells. (A) MKN-45 (left) and AGS (right) cell lysates were separated by SDS-PAGE and analyzed by Western blotting with the indicated antibodies. GAPDH was used as a loading control. (B) and (C) The values of the band intensities represented the densitometric estimation of each band normalized to GAPDH from the MKN-45 (B) and AGS (C) cells $\left({ }^{*} \mathrm{P}<0.01\right)$.

\section{Discussion}

In this study, we report the effects of sh-MARCH8-induced knockdown of endogenous MARCH8 in human GC cells, indicating that appropriate levels of MARCH8 expression are essential for the survival and maintenance of GC cells. Cancer is a multifactorial process, and many molecular alterations have been shown to influence tumor initiation and development through abnormal gene expression or protein alterations. In 2017, more than 1.5 million cases of GC are expected in the world, 38\% of which are expected to occur in China and $44 \%$ in 24 countries that belong to the International Agency for Research On Cancer (IARC) [51]. Although the prevalence is declining, GC is the fourth most common cancer worldwide, accounting for approximately $10 \%$ of invasive cancers, making it the third leading cause of cancer mortalities.

Due to the difficulty of GC diagnosis and its low survival rate [51], new treatment strategies are needed. MKN-45 and AGS are human GC cell lines that are resistant to tumor necrosis factor and to other cytotoxic drugs. MARCH8 is a member of the MARCH family of membrane-bound E3 ubiquitin ligases (EC 6.3.2.19). MARCH enzymes add ubiquitin (see Online Mendelian Inheritance in Man [OMIM] database, omim.org, ID is 191339) to their target lysine residues in substrate proteins, thereby signaling these proteins' vesicular transport between membrane compartments. MARCH8 induces the internalization of several membrane glycoproteins $[23,24]$. In our study, we used MKN-45 and AGS cells to investigate the effects of sh-MARCH8 on their proliferation, migration and invasion. Our results showed a remarkable increase in MARCH8 expression in GC, which makes it a potential prognostic marker of GC. In MKN-45 and AGS cells, transfection of the sh-MARCH8 plasmid efficiently inhibited the expression of MARCH8. The reduction of MARCH8 significantly inhibited the proliferation of MKN-45 and AGS GC cells, and decreased both their migration and invasion. 


\section{Cellular Physiology Cell Physiol Biochem 2018;49:306-321

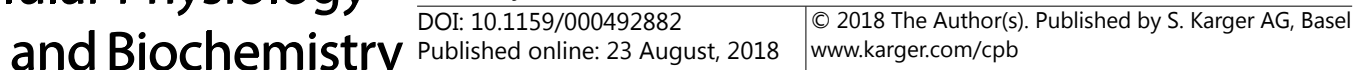 \\ Yin et al.: sh-MARCH8 Inhibits Gastric Cancer by PI3K}

Down-regulation of MARCH8 induced apoptosis of GC cells and altered the expression of apoptosis-related proteins. Our results suggested that the mechanism underlying these phenotypes involves sh-MARCH8 suppressing the activation of the PI3K and ß-catenin stat3 signaling pathways in gastric cancer cells. These results reflected a potential pathological role of this protein in GC.

Mitochondria-mediated cell apoptosis is the major apoptotic pathway and is most commonly mediated by a variety of protein-membrane and protein-protein interactions of the B-cell lymphoma 2 protein (BCL2) family. BCL2-associated X (BAX), a member of the BCL2 family, is a pro-apoptotic protein. Overexpression of BAX triggers the release of mitochondrial proteins that cleave caspase-3, thereby activating it to induce apoptosis [52]. In our study, we found that sh-MARCH8 transfection increased the BAX/BCL2 ratio in both MKN-45 and AGS cells and also increased the expression of caspase-3 p17. These results suggest that the loss of MARCH8 triggered apoptosis via a mitochondrial pathway. However, the BCL2 family proteins are regulated by many signaling pathways such as PI3K, wnt/ $\beta$ catenin and p53. In our study, MARCH8 knockdown changed the expression of BCL2 family proteins; however, there was no evidence showing that MARCH8 could directly regulate their expression levels. We concluded that MARCH8 regulated the apoptosis proteins indirectly through other signaling pathways.

To elucidate the mechanism of MARCH8's inhibition of MKN-45 and AGS cells, we studied the effects of sh-MARCH8 on PI3K pathway members. The PI3K/AKT/mTOR pathway is implicated in numerous cellular processes ranging from cell growth and survival to the promotion of angiogenesis $[44,53]$. The serine/threonine kinase AKT inhibits apoptosis and mediates cell survival by activating PI3K [54]. Another kinase, mTOR, is expressed in most mammalian cells [55], and it is involved in the inhibition of autophagy and acts as a cellular sensor of nutrients and growth factors. Furthermore, mTOR is also an important effector in the PI3K signaling pathway [56]. ß-catenin stat3 signaling proteins belong to a family of secreted proteins that plays important roles in the development and maintenance of many tissues, and include ß-catenin E-cadherin, Cyclin D1 and stat3. ß-catenin stat3 signaling proteins also control kinase-signaling pathways. We discovered that sh-MARCH8 transfection decreased the amounts of the phosphorylated forms of p-AKT and mTOR via the phosphorylation of PI3K. Since PI3K activation inhibits GSK3 $\beta$, the increased expression of GSK3 $\beta$ and the decreased expression of P70 further confirmed this conclusion.

\section{Conclusion}

Our findings indicated that MARCH8 could be considered a potent GC inhibitor and could be potentially used as a supplementary agent in GC therapy. The underlying mechanism of the interaction between MARCH8 and conventional cancer therapies requires further research in the future.

\section{Disclosure Statement}

No conflicts of interest exist.

\section{References}

1 McWhorter JE: Malignant Epithelial Tumors of the Neck of Unknown Origin. Ann Surg 1929;90:1-14.

2 Feinberg AP, Ohlsson R, Henikoff S: The epigenetic progenitor origin of human cancer. Nat Rev Genet 2006;7:21-33. 


\section{Cellular Physiology Cell Physiol Biochem 2018;49:306-321 and Biochemistry \begin{tabular}{l|l} 
DOI: 10.1159/000492882 & $\begin{array}{l}\text { C } 2018 \text { The Author(s). Published by S. Karger AG, Basel } \\
\text { www.karger.com/cpb }\end{array}$
\end{tabular} \\ \begin{tabular}{l|l} 
Published online: 23 August, 2018 www.karger.com/cpb \\
\hline Yin et al: sh-MARCH8 Inhibits Gastric Cancer by PI3K
\end{tabular}}

3 Takeno SS, Leal MF, Lisboa LC, Lipay MV, Khayat AS, Assumpcao PP, Burbano RR, Smith Mde A: Genomic alterations in diffuse-type gastric cancer as shown by high-resolution comparative genomic hybridization. Cancer Genet Cytogenet 2009;190:1-7.

4 Burbano RR, Assumpcao PP, Leal MF, Calcagno DQ Guimaraes AC, Khayat AS, Takeno SS, Chen ES, De Arruda Cardoso Smith M: C-MYC locus amplification as metastasis predictor in intestinal-type gastric adenocarcinomas: CGH study in Brazil. Anticancer Res 2006;26:2909-2914.

5 Gigek CO, Chen ES, Calcagno DQ Wisnieski F, Burbano RR, Smith MA: Epigenetic mechanisms in gastric cancer. Epigenomics 2012;4:279-294.

-6 Calcagno DQ, Gigek CO, Chen ES, Burbano RR, Smith Mde A: DNA and histone methylation in gastric carcinogenesis. World J Gastroenterol 2013;19:1182-1192.

7 Pontes TB, Chen ES, Gigek CO, Calcagno DQ, Wisnieski F, Leal MF, Demachki S, Assumpcao PP, Artigiani R, Lourenco LG, Burbano RR, Arruda Cardoso Smith M: Reduced mRNA expression levels of MBD2 and MBD3 in gastric carcinogenesis. Tumour Biol 2014;35:3447-3453.

8 Wisnieski F, Calcagno DQ Leal MF, Chen ES, Gigek CO, Santos LC, Pontes TB, Rasmussen LT, Payao SL, Assumpcao PP, Lourenco LG, Demachki S, Artigiani R, Burbano RR, Smith MC: Differential expression of histone deacetylase and acetyltransferase genes in gastric cancer and their modulation by trichostatin A. Tumour Biol 2014;35:6373-6381.

$>9$ Wisnieski F, Leal MF, Calcagno DQ, Santos LC, Gigek CO, Chen ES, Artigiani R, Demachki S, Assumpcao PP, Lourenco LG, Burbano RR, Smith MC: BMP8B Is a Tumor Suppressor Gene Regulated by Histone Acetylation in Gastric Cancer. J Cell Biochem 2017;118:869-877.

$>10$ da Silva Oliveira KC, Thomaz Araujo TM, Albuquerque CI, Barata GA, Gigek CO, Leal MF, Wisnieski F, Rodrigues Mello Junior FA, Khayat AS, de Assumpcao PP, Rodriguez Burbano RM, Smith MC, Calcagno DQ: Role of miRNAs and their potential to be useful as diagnostic and prognostic biomarkers in gastric cancer. World J Gastroenterol 2016;22:7951-7962.

-11 Ferlay J, Soerjomataram I, Dikshit R, Eser S, Mathers C, Rebelo M, Parkin DM, Forman D, Bray F: Cancer incidence and mortality worldwide: Sources, methods and major patterns in GLOBOCAN 2012. International Journal of Cancer 2015;136:E359.

12 Graham DY: Helicobacter pylori Update: Gastric Cancer, Reliable Therapy, and Possible Benefits. Gastroenterology 2015;148:719.

13 Guggenheim DE, Shah MA: Gastric cancer epidemiology and risk factors. Journal of surgical oncology 2013;107:230-236.

14 Neugut AI, Hayek M, Howe G: Epidemiology of gastric cancer. World Journal of Gastroenterology 2006;23:281.

15 Fujimoto S, Takahashi M, Kobayashi K, Kokubun M, Shrestha RD, Kiuchi S, Konno C: Metabolic changes in cimetidine treatment for scald injury on the peritoneo-serosal surface in far-advanced gastric cancer patients treated by intraperitoneal hyperthermic perfusion. Surgery Today 1993;23:396.

16 Wang S, Wang Y, Zhang K: Relation between metabolic changes of free radicals and differentiation of gastric cancer. Guangdong Medical Journal 2002;23:137-138.

17 Mclean MH, El-Omar EM: Genetics of gastric cancer. Nature Reviews Gastroenterology \& Hepatology 2014;11:664-674.

18 Oliveira C, Seruca R, Carneiro F: Genetics, pathology, and clinics of familial gastric cancer. Int J Surg Pathol 2006;14:21.

19 Figueiredo C, Garcia-Gonzalez MA, Machado JC: Molecular pathogenesis of gastric cancer. Helicobacter 2013;18:28-33.

20 Cancer Genome Atlas Research N: Comprehensive molecular characterization of gastric adenocarcinoma. Nature 2014;513:202-209.

21 Lei Z, Tan IB, Das K, Deng N, Zouridis H, Pattison S, Chua C, Feng Z, Guan YK, Ooi CH, Ivanova T, Zhang S, Lee M, Wu J, Ngo A, Manesh S, Tan E, Teh BT, So JB, Goh LK, et al.: Identification of molecular subtypes of gastric cancer with different responses to PI3-kinase inhibitors and 5-fluorouracil. Gastroenterology 2013;145:554-565.

22 Cristescu R, Lee J, Nebozhyn M, Kim KM, Ting JC, Wong SS, Liu J, Yue YG, Wang J, Yu K, Ye XS, Do IG, Liu S, Gong L, Fu J, Jin JG, Choi MG, Sohn TS, Lee JH, Bae JM, et al.: Molecular analysis of gastric cancer identifies subtypes associated with distinct clinical outcomes. Nat Med 2015;21:449-456. 


\section{Cellular Physiology Cell Physiol Biochem 2018;49:306-321 \begin{tabular}{ll|l} 
and Biochemistry Published online: 23 August, 2018 & $\begin{array}{l}\text { (c) } 2018 \text { The Author(s). Published by S. Karger AG, Basel } \\
\text { www.karger.com/cpb }\end{array}$
\end{tabular}}

Yin et al.: sh-MARCH8 Inhibits Gastric Cancer by PI3K

23 Goto E, Ishido S, Sato Y, Ohgimoto S, Ohgimoto K, Nagano-Fujii M, Hotta H: c-MIR, a human E3 ubiquitin ligase, is a functional homolog of herpesvirus proteins MIR1 and MIR2 and has similar activity. J Biol Chem 2003;278:14657-14668.

24 Bartee E, Mansouri M, Hovey Nerenberg BT, Gouveia K, Fruh K: Downregulation of major histocompatibility complex class I by human ubiquitin ligases related to viral immune evasion proteins. J Virol 2004;78:11091120.

25 Ohmura-Hoshino M, Goto E, Matsuki Y, Aoki M, Mito M, Uematsu M, Hotta H, Ishido S: A novel family of membrane-bound E3 ubiquitin ligases. J Biochem 2006;140:147-154.

-26 Lehner PJ, Hoer S, Dodd R, Duncan LM: Downregulation of cell surface receptors by the K3 family of viral and cellular ubiquitin E3 ligases. Immunol Rev 2005;207:112-125.

-27 Nathan JA, Lehner PJ: The trafficking and regulation of membrane receptors by the RING-CH ubiquitin E3 ligases. Exp Cell Res 2009;315:1593-1600.

-28 Wang X, Herr RA, Hansen T: Viral and cellular MARCH ubiquitin ligases and cancer. Semin Cancer Biol 2008;18:441-450.

29 Baravalle G, Park H, McSweeney M, Ohmura-Hoshino M, Matsuki Y, Ishido S, Shin JS: Ubiquitination of CD86 is a key mechanism in regulating antigen presentation by dendritic cells. J Immunol 2011;187:2966-2973.

-30 Bartee E, Eyster CA, Viswanathan K, Mansouri M, Donaldson JG, Fruh K: Membrane-Associated RING-CH proteins associate with Bap31 and target CD81 and CD44 to lysosomes. PLoS One 2010;5:e15132.

-31 Matsuki Y, Ohmura-Hoshino M, Goto E, Aoki M, Mito-Yoshida M, Uematsu M, Hasegawa T, Koseki H, Ohara O, Nakayama M, Toyooka K, Matsuoka K, Hotta H, Yamamoto A, Ishido S: Novel regulation of MHC class II function in B cells. EMBO J 2007;26:846-854.

32 De Gassart A, Camosseto V, Thibodeau J, Ceppi M, Catalan N, Pierre P, Gatti E: MHC class II stabilization at the surface of human dendritic cells is the result of maturation-dependent MARCH I down-regulation. Proc Natl Acad Sci U S A 2008;105:3491-3496.

-33 Chen R, Li M, Zhang Y, Zhou Q Shu HB: The E3 ubiquitin ligase MARCH8 negatively regulates IL-1betainduced NF-kappaB activation by targeting the IL1RAP coreceptor for ubiquitination and degradation. Proc Natl Acad Sci U S A 2012;109:14128-14133.

-34 Fujita H, Iwabu Y, Tokunaga K, Tanaka Y: Membrane-associated RING-CH (MARCH) 8 mediates the ubiquitination and lysosomal degradation of the transferrin receptor. J Cell Sci 2013;126:2798-2809.

-35 van de Kooij B, Verbrugge I, de Vries E, Gijsen M, Montserrat V, Maas C, Neefjes J, Borst J: Ubiquitination by the membrane-associated RING-CH-8 (MARCH-8) ligase controls steady-state cell surface expression of tumor necrosis factor-related apoptosis inducing ligand (TRAIL) receptor 1. J Biol Chem 2013;288:66176628.

-36 Tang Z, Li C, Kang B, Gao G, Li C, Zhang Z: GEPIA: a web server for cancer and normal gene expression profiling and interactive analyses. Nucleic Acids Research 2017;45:W98-W102.

-37 Kim MH, Rebbert ML, Ro H, Won M, Dawid IB: Cell adhesion in zebrafish embryos is modulated by March 8. PLoS One 2014;9:e94873.

-38 Ishido S, Goto E, Matsuki Y, Ohmura-Hoshino M: E3 ubiquitin ligases for MHC molecules. Curr Opin Immunol 2009;21:78-83.

-39 Lapaque N, Jahnke M, Trowsdale J, Kelly AP: The HLA-DRalpha chain is modified by polyubiquitination. J Biol Chem 2009;284:7007-7016.

40 Iyengar PV, Hirota T, Hirose S, Nakamura N: Membrane-associated RING-CH 10 (MARCH10 protein) is a microtubule-associated E3 ubiquitin ligase of the spermatid flagella. J Biol Chem 2011;286:39082-39090.

41 Yogo K, Tojima H, Ohno JY, Ogawa T, Nakamura N, Hirose S, Takeya T, Kohsaka T: Identification of SAMT family proteins as substrates of MARCH11 in mouse spermatids. Histochem Cell Biol 2012;137:53-65.

42 Morokuma Y, Nakamura N, Kato A, Notoya M, Yamamoto Y, Sakai Y, Fukuda H, Yamashina S, Hirata Y, Hirose S: MARCH-XI, a novel transmembrane ubiquitin ligase implicated in ubiquitin-dependent protein sorting in developing spermatids. J Biol Chem 2007;282:24806-24815.

43 Gross A, McDonnell JM, Korsmeyer SJ: BCL-2 family members and the mitochondria in apoptosis. Genes Dev 1999;13:1899-1911.

44 Martinou JC, Youle RJ: Mitochondria in apoptosis: Bcl-2 family members and mitochondrial dynamics. Dev Cell 2011;21:92-101.

45 Rameh LE, Cantley LC: The role of phosphoinositide 3-kinase lipid products in cell function. J Biol Chem 1999;274:8347-8350. 


\section{Cellular Physiology Cell Physiol Biochem 2018;49:306-321 \begin{tabular}{l|l} 
DOI: 10.1159/000492882 & $\begin{array}{l}\text { O 2018 The Author(s). Published by S. Karger AG, Basel } \\
\text { www.karger.com/cpb }\end{array}$
\end{tabular}}

Yin et al.: sh-MARCH8 Inhibits Gastric Cancer by PI3K

46 Downward J: Mechanisms and consequences of activation of protein kinase B/Akt. Curr Opin Cell Biol 1998;10:262-267.

47 Shaw RJ, Cantley LC: Ras, PI(3)K and mTOR signalling controls tumour cell growth. Nature 2006;441:424430.

48 Raught B, Gingras AC, Sonenberg N: The target of rapamycin (TOR) proteins. Proc Natl Acad Sci U S A 2001;98:7037-7044.

-49 Jefferies HB, Fumagalli S, Dennis PB, Reinhard C, Pearson RB, Thomas G: Rapamycin suppresses 5’TOP mRNA translation through inhibition of p70s6k. EMBO J 1997;16:3693-3704.

-50 Li J, Yen C, Liaw D, Podsypanina K, Bose S, Wang SI, Puc J, Miliaresis C, Rodgers L, McCombie R, Bigner SH, Giovanella BC, Ittmann M, Tycko B, Hibshoosh H, Wigler MH, Parsons R: PTEN, a putative protein tyrosine phosphatase gene mutated in human brain, breast, and prostate cancer. Science 1997;275:1943-1947.

51 Richman DM, Tirumani SH, Hornick JL, Fuchs CS, Howard S, Krajewski K, Ramaiya N, Rosenthal M: Beyond gastric adenocarcinoma: Multimodality assessment of common and uncommon gastric neoplasms. Abdom Radiol (NY) 2017;42:124-140.

52 Eskes R, Antonsson B, Osen-Sand A, Montessuit S, Richter C, Sadoul R, Mazzei G, Nichols A, Martinou JC: Bax-induced cytochrome $\mathrm{C}$ release from mitochondria is independent of the permeability transition pore but highly dependent on Mg2+ ions. J Cell Biol 1998;143:217-224.

53 Wang Z, Wang N, Han S, Wang D, Mo S, Yu L, Huang H, Tsui K, Shen J, Chen J: Dietary compound isoliquiritigenin inhibits breast cancer neoangiogenesis via VEGF/VEGFR-2 signaling pathway. PLoS One 2013;8:e68566.

54 Stal O, Perez-Tenorio G, Akerberg L, Olsson B, Nordenskjold B, Skoog L, Rutqvist LE: Akt kinases in breast cancer and the results of adjuvant therapy. Breast Cancer Res 2003;5:R37-44.

55 Brown EJ, Albers MW, Shin TB, Ichikawa K, Keith CT, Lane WS, Schreiber SL: A mammalian protein targeted by G1-arresting rapamycin-receptor complex. Nature 1994;369:756-758.

-56 Ersahin T, Tuncbag N, Cetin-Atalay R: The PI3K/AKT/mTOR interactive pathway. Mol Biosyst 2015;11:1946-1954. 